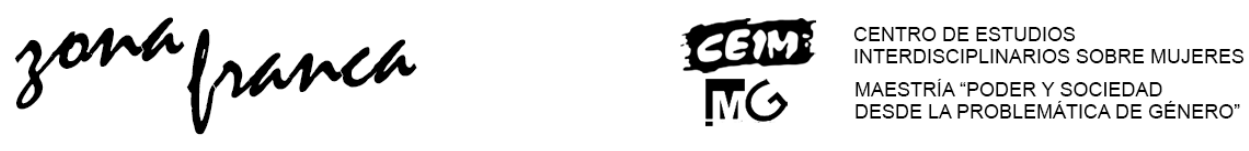

\title{
La concientización: un arma radical
}

Kathie Sarachild *

Lo que sigue a continuación es una compilación y ampliación del texto, las notas y los comentarios de una charla que ofreció Kathie Sarachild sobre la concientización en la Primera Conferencia de Azafatas por los Derechos de las Mujeres en Nueva York, el 12 marzo de 1973. Sarachild delineó el programa original para "la concientización feminista radical" que fuera presentado en la Primera Conferencia Nacional de la Liberación de las Mujeres el 27 de noviembre de 1968 en Chicago.

\section{LA IDEA}

Para poder comprender de qué se trata la concientización feminista, es importante recordar que comenzó como un programa entre mujeres que se consideraban radicales.

Pero antes de continuar, examinemos la palabra "radical". Es una palabra que se usa a menudo para sugerir "extremismo", pero realmente no es eso lo que significa. El diccionario dice que radical significa raíz, ya que proviene de la palabra latina "raíz". Y eso es lo que queríamos decir al llamarnos radicales. Nos interesaba llegar a la raíz de los problemas en la sociedad. Se podría decir que queríamos arrancar los yuyos del jardín desde las raíces, no solamente arrancar las hojas de la parte superior para hacer que las cosas se vean

* Sarachild, Kathie. "Consciousness-Raising: A Radical Weapon," in Feminist Revolution, New York: Random House, c1978, pp.144-150. Traducción: Verónica Storni Fricke. Revisión crítica: Ana María Bach. 
momentáneamente bien. El movimiento "Liberación de las Mujeres" (Women's Liberation) fue comenzado por mujeres que se consideraban radicales en este sentido.

Nuestra meta en la formación de un grupo de liberación de mujeres fue comenzar un movimiento masivo de mujeres para poner fin a las barreras de segregación y discriminación basadas en el sexo. Sabíamos que un pensamiento y una acción radicales serían necesarios para lograrlo. También creímos necesario que en nuestras reuniones de los grupos de Liberación de Mujeres los hombres estuvieran excluidos.

Con el propósito de lograr un enfoque radical, para llegar a la raíz, parecía lógico que tuviésemos que estudiar la situación de las mujeres, no sólo el accionar al azar. El cómo lograrlo de la mejor manera surgió en el grupo de liberación de las mujeres al que pertenecía, Mujeres Radicales de Nueva York (New York Radical Women), uno de los primeros en el país, poco después de la formación del grupo. Estábamos planificando nuestra primera acción pública y sin querer entramos en una discusión acerca de qué hacer después. Una mujer del grupo, Ann Forer, dijo: "Creo que tenemos mucho más para hacer en el área de nuestra concientización.” “¿Concientización?”, me pregunté qué quería decir con eso. Nunca lo había escuchado antes aplicado a las mujeres. "Sólo he comenzado a pensar en las mujeres como un grupo oprimido," continuó, "y cada día, estoy aprendiendo más acerca de esto; mi concientización aumenta."

En realidad, por mi parte, no consideraba que había empezado a pensar acerca de la opresión de las mujeres. De hecho, me veía a mí misma como 
habiendo pensado mucho sobre el tema, durante bastante tiempo, y que también había realizado muchas lecturas. Pero entonces Ann prosiguió dando un ejemplo de algo que ella había notado y que resultó ser una manera más profunda de verlo para mí también.

"Yo pienso mucho acerca de ser atractiva," dijo Ann. "La gente no encuentra el verdadero yo de una mujer atractiva." Y luego dio algunos ejemplos. Por mi parte, permanecí sentada escuchando cómo describía todas las maneras falsas en que las mujeres tienen que actuar: jugando a ser tontas, siempre siendo agradables, siempre tratando de ser buenas, sin mencionar lo que debíamos hacer con nuestros cuerpos, con las ropas y zapatos que usábamos, las dietas a las que nos sometíamos, perdiendo la vista por no usar anteojos, todo para que los hombres no encontraran nuestro verdadero yo, nuestra libertad humana, nuestra humanidad básica "atractiva". Y me di cuenta que aún podía comprender un montón acerca de cómo entender y describir la opresión particular de las mujeres de forma que llegase a otras mujeres de la misma manera que me había llegado a mí. El grupo entero se conmovió como yo, y decidimos en el momento que lo que necesitábamos, en las palabras de Ann, era "concientizarnos más".

En la siguiente reunión hubo una discusión en el grupo acerca de cómo lograrlo. Una mujer, Peggy Dobbins, dijo que lo que ella quería hacer era un estudio muy intensivo de toda la literatura sobre la cuestión de si realmente había diferencias biológicas entre los hombres y las mujeres. Esa idea me causó enojo. 
"Creo que sería una pérdida de tiempo," dije. "Por cada estudio científico que citemos, la oposición puede encontrar sus estudios científicos para citar. Además, la pregunta es qué queremos ser, qué creemos ser, no lo que algunas autoridades en el nombre de la ciencia están discutiendo acerca de lo que somos. Es científicamente imposible distinguir las diferencias biológicas entre hombres y mujeres, si hubiese algunas además de las obviamente físicas, a menos que todos los factores sociales y políticos que se aplican a los hombres y mujeres sean iguales. Todo lo que debemos saber y probar, podemos obtenerlo de las realidades de nuestras vidas. Por ejemplo, con respecto al tema de la inteligencia de las mujeres. Sabemos a través de nuestra experiencia que las mujeres simulamos ser tontas ante los hombres, porque si somos demasiado inteligentes, no les agradaremos. Lo sé porque lo hice. Todas lo hicimos. Por ello, podemos simplemente deducir que las mujeres son más inteligentes que los hombres piensan, y que hay muchas mujeres que son mucho más inteligentes de lo que aparentan y más inteligentes que nadie, excepto ellas mismas, y tal vez algunas de sus amigas lo saben."

Al final, el grupo decidió concientizarse estudiando las vidas de las mujeres a través de temas como la infancia, los empleos, la maternidad, etc. Leeríamos lo que quisiésemos y aquello que considerásemos importante. Pero nuestro punto de inicio para el debate, además de la prueba de exactitud de lo que dijesen cualquiera de los libros, sería la experiencia real que nosotras teníamos en estas áreas. Una de las preguntas, sugeridas por Ann Forer, que nosotras traeríamos todo el tiempo a nuestros estudios sería: quién y qué tiene interés en mantener la opresión en nuestras vidas. El tipo de acciones en el que los 
grupos deberían involucrarse, decidimos en ese momento, basándonos en una idea de Carol Hanisch, otra componente del grupo, serían las de concientización... acciones llevadas a lo público con el propósito específico de desafiar las ideas viejas y despertar nuevas; los mismos temas del feminismo que estábamos estudiando. Decidimos que nuestro rol no sería el de ser ni una “organización de servicio", ni tampoco una "organización de membrecía”. En efecto, de lo que estábamos hablando es de ser, cómo explicó Carol, una acción "de ataque" ("zap"), un grupo de agitación política y de educación, algo parecido a lo que había sido el Comité de coordinación no-violento estudiantil (Student Non-Violent Coordinating Committee, S.N.C.C.) Seríamos las primeras en decir y hacer lo que no nos atrevemos: lo que las mujeres realmente sienten y quieren. El primer trabajo, entonces, era elevar la conciencia y el entendimiento, los propios y los de los demás, conciencia que alentaría a la gente a organizarse y actuar a escala masiva.

La decisión de enfatizar nuestros sentimientos y experiencias como mujeres y de poner a prueba las generalizaciones y lecturas que hiciéramos a través de nuestra propia experiencia era, en realidad, el método científico de investigación. En efecto, estábamos repitiendo el desafío que la ciencia del siglo XVII había hecho a la escolástica: "estudien la naturaleza, no los libros," y someter las teorías a la prueba de la práctica viva y de la acción. Era también un método de organización radical probado por otras revoluciones. Estábamos aplicando, a las mujeres y a nosotras mismas como organizadoras de la liberación femenina, la práctica que un número de nosotras había aprendido 
como organizadoras del movimiento por los derechos civiles en el Sur, en los comienzos de los sesenta.

La concientización, al estudiar toda la gama de las vidas de las mujeres, comenzando con la realidad completa de la propia, es también una manera de mantener el movimiento radical al prevenir que se desvíe de su propósito en la consideración de reformas de un solo tema o en la organización de un único problema. Sería una forma de llevar la teoría acerca de las mujeres mucho más lejos de lo logrado antes, una base para lograr una solución radical para las mujeres aún no obtenido en ninguna parte.

Parecía claro que saber cómo nuestras propias vidas se relacionaban con la condición general de las mujeres nos harían mejores luchadoras en nombre de todas las mujeres en su conjunto. Sentíamos que todas las mujeres tendrían que ver la lucha de las mujeres como propia, no simplemente como algo para ayudar a "otras mujeres", que ellas tendrían que ver esta verdad acerca de sus propias vidas antes de que luchen de una manera radical por cualquier otra. "Vayan a luchar contra sus propios opresores," Stockel Carmicha el había dicho a los blancos que trabajaban por los derechos civiles de los negros cuando el movimiento del poder negro comenzó. "No te radicalizás luchando las batallas de otra gente," como lo expresó Beverly Jones en el ensayo pionero "Hacia un Movimiento de Liberación femenina" ("Toward A Female Liberation Movement") 


\section{LA RESISTENCIA}

Ahora bien, hubo una tremenda resistencia a que simplemente las mujeres estudiemos nuestra situación, especialmente sin los hombres en la sala. Al principio habíamos emprendido nuestro estudio para lograr una mejor acción. No nos habíamos dado cuenta que el sólo estudiar este tema y nombrar el problema, y los problemas, sería una acción radical en sí misma, una acción tan radical que engendraba una oposición tremenda y persistente desde sectores que todavía logran asombrarme. La oposición generalmente tomaba la forma de malinterpretaciones y distorsiones de lo que estábamos haciendo de tal manera que ninguna cantidad de explicaciones de nuestra parte podían corregir. Los métodos y supuestos detrás de la concientización crecieron esencialmente tanto desde la tradición científica como de la política radical, pero cuando la aplicábamos a las situaciones de las mujeres, un gran número de gente considerados "científicos" y "radicales", especialmente hombres, simplemente no podían verlo.

Áreas completas de las vidas de las mujeres se declararon fuera de los límites de la discusión. Los temas de los que hablábamos en nuestros grupos fueron desechados como "insignificantes" o "no políticos." A menudo estas eran las áreas claves en términos de cómo las mujeres están oprimidas en tanto un grupo particular, como las tareas domésticas, el cuidado de lo/as niño/as y el sexo. Todo/as desde lo/as republicano/as hasta lo/as comunistas dijeron que estaban de acuerdo con que igual pago para igual trabajo era una tema válido y merecía apoyo. Pero cuando las mujeres quisimos descubrir por qué no estábamos obteniendo igual paga por igual trabajo en ningún lado, y quisimos 
echar un vistazo en estas áreas, entonces lo que estábamos haciendo no era política, economía, ni siquiera estudio, sino "terapia," algo que las mujeres debían elaborar para ellas mismas individualmente.

Cuando comenzamos a analizar estos problemas en términos de chovinismo masculino, repentinamente fuimos la prueba viviente de cuán atrasadas estábamos las mujeres. Aunque habíamos efectuado acciones políticas radicales y tomado riesgos muchas veces antes, y continuaríamos actuando una y otra vez, cuando discutíamos el machismo éramos de repente simplemente mujeres que nos quejábamos todo el tiempo, nos quedábamos en el ámbito personal y nunca actuábamos.

Algunas personas dijeron directamente que creían que lo que hacíamos era peligroso. Cuando llevamos ejemplos meramente concretos de nuestras vidas acerca de discriminación en contra de las mujeres o de explotación de mujeres, fuimos acusadas de "odiar a los hombres" o ser "amargas". Estos eran más esfuerzos para mantener los temas e ideas que estábamos discutiendo fuera del ámbito de los temas de estudio y debates genuinos al definirlos como ilusiones psicológicas.

Y cuando intentamos describir las realidades de nuestras vidas de maneras determinadas, por lógicas que fueren, por ejemplo, cuando dijimos que los hombres oprimían a las mujeres, o que todos los hombres estaban entre los beneficiarios de la opresión de las mujeres, algunas personas realmente se disgustaron. “¡No pueden decir que los hombres son los opresores de las mujeres! ¡Los hombres también están oprimidos! ¡Y las mujeres discriminan a las mujeres!" Ahora bien, no hace falta aclarar que si las 
mujeres tenemos un estatus secundario en la sociedad, comparado con los hombres, y somos tratadas como criaturas secundarias, entonces los beneficiarios son aquellos que poseen el estatus primario.

Nuestras reuniones eran llamadas charlas de café, reuniones de gallinas o sesiones de perras. Respondimos, "sí, perras, hermanas, perras," y las charlas de café ("coffee klatches") fueron una forma histórica de resistencia a la opresión. Las denominaciones y ataques eran para nosotras una constante fuente de irritación y a veces de asombro al provenir a menudo de otras personas radicales que nosotras creímos que recibirían bien este nuevo movimiento masivo de un grupo oprimido. Peor aún, las mentiras previnieron a algunas mujeres con las que nos hubiera gustado encontrarnos para que supieran qué era lo que estábamos haciendo.

\section{EL PROGRAMA}

No se podía negar, sin embargo, que nosotras estábamos aprendiendo mucho de las discusiones y que las encontrábamos muy estimulantes. De los encuentros de concientización surgieron los escritos que formularon la teoría básica del movimiento de liberación de las mujeres. Shulamith Firestone, escribió el libro La Dialéctica del Sexo (The Dialectic of Sex), Anne Koedt, escribió el ensayo "El mito del orgasmo vaginal" ("The Myth of the Vaginal Orgasm"), Pat Mainardi, escribió el ensayo "La política del trabajo doméstico" ("The Politics of Housework"), Carol Hanisch, escribió el ensayo, "Lo personal es político" ("The Personal is Political"), Kate Millett, escribió Política Sexual (Sexual Politics), Cindy Cisler, lideró la revolucionaria ley del aborto en Nueva 
York, Rosalyn Baxandall, Irene Peslikis, Ellen Willis, Robin Morgan y muchas otras participaron en estas discusiones. Muchas de nosotras pensábamos que esto sólo era el comienzo de una comprensión radical de las mujeres, y de otros temas como los de clase, raza y cambio revolucionario.

Nuestro grupo crecía rápidamente. Otras mujeres estaban tan fascinadas como nosotras con la idea de que pudiéramos hacer algo desde el punto de vista político sobre aspectos de nuestras vidas como mujeres, algo que nunca habíamos pensado que podía ser tratado políticamente, así es que pensamos que tendríamos que trabajar lo mejor que pudiéramos por nuestra cuenta. La mayoría de estas cuestiones no eran tratados en la Organización Nacional de las Mujeres (National Organization for Women, NOW ${ }^{1}$ ) ¿Era porque consideraban a estos temas como "insignificantes" o por que realmente impactaban en el corazón de áreas de profunda humillación para todas las mujeres? Tampoco constituía NOW (la Organización Nacional de las Mujeres) entonces grupos de concientización. Esto sólo ocurrió después de 1968, cuando los grupos nuevos y más radicales se formaron, con una perspectiva masiva. La primera acción pública de nuestro grupo después de publicar un diario, fue un intento de que nuestras ideas sobre uno de esos temas denominados "insignificantes" tuvieran un alcance masivo: el tema de la apariencia. Protestamos e hicimos piquetes en contra del concurso para Miss América, arrojamos zapatos de taco, ligas y otros objetos femeninos de tortura en un contenedor de basura de libertad. Fue esta acción de 1968 la que despertó por primera vez una conciencia generalizada acerca del nuevo

\footnotetext{
${ }^{1}$ La NOW había sido fundada por Betty Friedan y sus seguidoras. Se consideraba una organización de tinte liberal que en esos primeros tiempos no trataban el tema del aborto, por ejemplo. [Nota de AMB]
} 
"Movimiento de Liberación Femenina", captando

el interés mundial y dándole al movimiento su nombre.

$$
\text { Los grupos de estudio estaban }
$$

radicalizando nuestra propia conciencia y de pronto nos dimos cuenta que las mujeres podíamos hacer a escala masiva lo que estábamos haciendo en nuestro propio grupo, por lo que la siguiente acción radical lógica sería divulgarlo. Esta forma de estudio sería parte de lo necesario para lograr la liberación de las mujeres a escala masiva. El patrón de obstáculos a la concientización también se estaba tornando cada vez más claro. Por eso bosquejé un trabajo acerca de esto, sobre cuán políticas estas denominadas "reuniones de perras" podían ser, sugiriendo qué información importante aún debíamos obtener para nuestra lucha, estudiando las experiencias y los sentimientos de las mujeres, describiendo algunos de los obstáculos y proponiendo que las mujeres comiencen por todos lados.
Raíces de la concientización

Pero ¿por qué debería yo, en un vasto océano de libros por el que las mentes de los hombres están turbadas y fatigadas...exponer esta noble filosofía a ser condenada y despedazada por la maldición de aquellos que ya están comprometidos con opiniones de otros hombres, o son tontos corruptores de las buenas artes, idiotas eruditos, gramáticos, sofistas, adversarios y gente perversa?...Pero solo a ustedes, verdaderos filósofos, hombres honrados que buscan conocimiento no sólo de los libros sino de las cosas mismas, he dirigido estos principios magnéticos. William Gilbert, Prefacio de Sobre el magnetismo, 1628

Tuvimos que adoptar el nuevo método que los médicos utilizan en algún momento, cuando son llamados a atender a un paciente desesperadamente enfermo, inconsciente de su dolor y sufrimiento. Tuvimos que describir a las mujeres su propia posición, explicarles las cargas que llevaban tan pesadamente sobre ellas, y por estos medios, como un saludable irritante, despertamos la opinión pública sobre el tema, y a través de la opinión pública sobre el tema actuamos sobre la legislación. Ernestine Rose, 1860, Historia de sufragio de la mujer

Todo el conocimiento se origina en la percepción del mundo externo objetivo a través de los órganos de los sentidos humanos. Quien niegue tal percepción, niega la experiencia directa o niega la participación personal en la práctica que cambia la realidad, no es materialista. Mao Tsetung, 1937, "Sobre la práctica"

No se puede dar a la gente un programa hasta que se da cuenta de que necesita uno, y hasta que se dan cuenta de que todos los programas existentes no ... van a producir ... resultados. Lo que nos gustaría hacer ... es entrar en nuestro problema y sólo analizar ... y cuestionar cosas que uno no entiende para que podamos... obtener una mejor imagen de lo que enfrentamos. Si usted da a la gente un conocimiento profundo de lo que se enfrentan, y las causas básicas que lo producen, van a crear sus propios programas, $Y$ cuando la gente crea un programa, usted consigue la acción. Malcom X, 1964, Malcom X habla.

\section{SEIS AÑOS MÁS TARDE}


Desde 1967, la concientización se ha transformado en uno de los programas educativos principales de organización del movimiento de liberación femenina. Los grupos feministas y las mujeres en forma individual, que al principio creyeron que no lo necesitaban, lo están haciendo. Al popularizarse la concientización, muchos otros grupos e individuos se han involucrado en ella y su naturaleza se ha modificado para adecuarse a distintos propósitos. El término concientización se ha usado ampliamente en contextos contradictorios. Un artículo reciente del New York Times se refirió a una reunión convocada por Henry Kissinger para hablar con los ejecutivos de las principales redes televisivas acerca del contenido de los programas como una "curiosa sesión de ‘concientización'” con el Secretario de Estado."

Hasta en el movimiento de liberación femenina hay todo tipo de promotores de la concientización, personas que son vistas como "expertas en el tema", otras que delinean todo tipo de pautas y reglas para su uso. En todo esto, el propósito original de la concientización, su conexión con el cambio revolucionario para las mujeres, frecuentemente se pierde. Es por ello que una mirada a los orígenes de la concientización provee una perspectiva tan importante.

El propósito de la liberación femenina era derrotar la supremacía masculina y dar igualdad a las mujeres. Creímos que esta era una tarea tan monumental. ¿Cómo encararla? La concientización parecía ser lo que se necesitaba.

La supremacía masculina de la clase dirigente (Establishment) y sus fuerzas de discriminación contra las mujeres que la concientización se propuso criticar, 
acusaron recibo del golpe. Ahora la oposición a la concientización frecuentemente viene disfrazada de apoyo, o de apoyo parcial. La clase dirigente está tratando de cambiar la concientización, debilitarla, diluirla, y sacarle fuerza para que no cause más cambios.

Ir a las fuentes, a las raíces históricas, al trabajo que puso el programa en acción es una de las maneras de combatir ese proceso. La fuente de poder de la concientización es el compromiso con un enfoque radical, con una solución radical. Lo que realmente sucedió en el programa original de concientización, que resultó ser tan provocativo, fue el pensamiento que estuvo por detrás, la literatura que el grupo original produjo y que forma el núcleo de experiencias a partir de las que se originan las demás enseñanzas. A partir de ella también podemos descubrir qué estuvo equivocado en el pensamiento original que permitió que algo de la organización se desviara del camino propuesto. Pero cualquier corrección en la idea original debe ser hecha para volver más afilada el arma de la concientización, no más débil.

\section{VERIFICAR LAS FUENTES ORIGINALES}

Las personas que comenzaron la concientización no se consideraban principiantes en la política, inclusive, en muchos casos, en el feminismo. Sin embargo, quisieron la concientización tanto para sí mismas como para las principiantes. La concientización fue vista tanto como un método para llegar a la verdad como un medio para la acción y la organización. Era un medio para que quienes organizaban hicieran un análisis de la situación, y también un medio para ser usado por aquellas personas que estaban organizando y que, a 
su vez, organizaban a otra gente. De manera similar, no era visto meramente como una etapa en el desarrollo del feminismo que conduciría a otra etapa, a una fase de acción, sino como una parte esencial de la estrategia feminista general.

Para iniciar la concientización nosotras, como organizadoras, le dimos prioridad en nuestras acciones y en el trabajo político. En ese sentido la consideramos como una primera etapa para despertar a las personas, para llevarlas al pensamiento y a la acción. Pero también la vimos como una fuente continua y progresiva de teoría e ideas para la acción. Asumimos, una suposición básica para la concientización, que la mayoría de las mujeres eran como nosotras, no diferentes, de manera tal que nuestro propio interés en discutir los problemas a que las mujeres nos enfrentamos y que más nos atañían, también interesaría a otras mujeres. Atrevernos a hablar de nuestras propias experiencias y sentimientos sería muy poderoso. Nuestra creciente conciencia feminista nos condujo a ese supuesto al revelarnos que todas las mujeres sufrimos opresión como mujeres y teníamos un interés común en darlo por teminado. Cualquier opción menor al enfoque radical del feminismo podría interesar a otras mujeres más de lo que nos interesaba este enfoque a nosotras, así es que no valdría la pena el esfuerzo probarlo. Sentimos que otras mujeres también responderían a lo que era radical, a pesar de que tal vez no se considerarían "radicales" debido a la distorsión generalizada del significado de esa palabra.

Desde los comienzos de la concientización, como pueden ver en el primer programa bosquejado en 1968, no hubo solamente un método de 
concientización. Lo que realmente cuenta en la concientización no son los métodos, sino los resultados. Los únicos "métodos" en la concientización son los principios políticos. Ellos son los principios radicales básicos de ir a las fuentes originales, tanto históricas como personales, yendo a las personas, a las mujeres mismas, y yendo a la experiencia para la teoría y la estrategia. La experiencia en la concientización no puede ser juzgada por la pericia en cualquier método supuesto sino por la pericia en obtener resultados, en producir conocimiento. ¡Es llamativo cuántas personas en las circunstancias correctas puede, de repente, transformarse en expertas por estos estándares! Uno de los descubrimientos excitantes de la concientización del Movimiento de Liberación Femenina ha sido ver cuánto conocimiento puede provenir de la simple honestidad y la puesta en común de las experiencias en una sala llena de mujeres interesadas.

La parafernalia de reglas y metodología, el nuevo dogma de "C-R" (en inglés siglas para concientización, "consciousness-raising" N.T.) que ha crecido en torno a la concientización en la medida en que se ha divulgado, ha tenido el efecto de crear intereses creados para los expertos en metodología, tanto profesionales (por ejemplo, psiquiatras) como aficionados. Hubo un número de "reglas" y "pautas" formalizadas para la concientización que fueron publicadas y distribuidas en los grupos de mujeres con aire de autoridad, como si representasen el programa original de la concientización. Pero el nuevo conocimiento es la fuente de la fortaleza y el poder de la concientización. Los métodos deben sólo servir a este propósito, para ser cambiados si no funcionan. 


\section{LOS PRINCIPIOS RADICALES DAN RESULTADOS}

I

Por ejemplo, el propósito de hacer una ronda en el lugar de reunión para escuchar el testimonio de cada mujer, una práctica común y excitante de la concientización, es para mantenerse enfocadas en un punto, volver la discusión a su tema principal después de explorar una tangente y recoger las experiencia de tantas personas como sea posible en la puesta en común del conocimiento. El propósito de escuchar a todas no se suponía que fuera el ser agradables o tolerantes o el desarrollar habilidades o la "habilidad para escuchar". Era aproximarse a la verdad. El conocimiento y la información harían posible que la gente fuese "capaz" de hablar. El propósito de escuchar los sentimientos y las experiencias

Citas

En mi opinión, buscar no significa nada en la pintura. Encontrar es la cosa. Picasso.

Los poetas negros deben buscar, pero no buscar demasiado en oscuras dulces cuevas, ni cazar escolopácidos por senderos psíquicos (como hacen los muchachos blancos) Etheridge Knight.

Estoy cansado de esas personas que siempre están experimentando, nunca descubriendo nada. Siempre están cambiando, siempre son lo mismo. Michael Goldman.) no era terapia, no era darle la oportunidad a alguien de sacarse un peso de encima... eso es algo para una amistad. Era escuchar lo que tenía para decir. La importancia de escuchar los sentimientos de una mujer consistía en analizar la situación de las mujeres colectivamente, no analizarla a ella. La idea no era cambiar a las mujeres, no era hacer "cambios internos" excepto en el sentido de saber más. Fueron y son las condiciones que las mujeres enfrentan, es la supremacía masculina lo que queremos cambiar.

Aunque generalmente muy provocativa, fascinante e informativa, "hacer la ronda en la sala" puede volverse insensibilizante, nada informativa, y hasta 
hacer fracasar el propósito de la concientización, si se la limita con reglas rígidas como "no interrumpir", "no irse por las ramas", "no generalizar." La idea de la concientización nunca fue poner fin a las generalizaciones, sino producir generalizaciones más verdaderas. La idea era tomar nuestros propios sentimientos y experiencias más seriamente que cualquiera de las teorías que no las clarificaban satisfactoriamente, y diseñar nuevas teorías que sí reflejaran la experiencia, los sentimientos y las necesidades reales de las mujeres.

La concientización, entonces, no es ni un fin en sí misma ni una etapa, ni un medio para un fin diferente, sino una parte significativa de un compromiso muy inclusivo de ganar y garantizar cambios radicales para las mujeres en la sociedad. La mirada de la concientización como un fin en sí mismo, que es lo que sucede cuando la concientización se transforma en una metodología, una psicología, es una distorsión tan severa y destructiva de la idea original y del poder del arma como el considerarla como una etapa. Como una mujer, Michal Goldman, lo expresara, "Me cansa la gente que está siempre experimentando, nunca descubriendo nada, siempre examinando, pero nunca viendo, siempre cambiando, siempre permaneciendo igual."

Tampoco la concientización supone, como algunas han sugerido, que el aumento de la conciencia, el conocimiento, o la educación por sí solos, pueden eliminar la supremacía masculina. En la concientización, a través de la experiencia compartida, una aprende que descubrir la verdad o que el nombrar lo que está sucediendo, es necesario pero no suficiente para hacer cambios. Con mayor comprensión, una descubre una nueva necesidad para la acción y nuevas posibilidades. Encontrar la solución a un problema se lleva a cabo a 
través de ambas, la teoría y la acción. Cada una conduce a la otra pero ambas son necesarias o el problema nunca se resuelve realmente.

\section{EL ACTIVISMO SIN SENTIDO}

El propósito de la concientización era llegar a las verdades más radicales acerca de la situación de las mujeres para tomar acción radical; pero el llamado a la "acción" puede a veces ser Una cuestión de concientización una manera de evitar el entendimiento y prevenir la acción radical. La acción llega cuando nuestra experiencia finalmente es verificada y clarificada. Hay una energía tremenda en la concientización, un entusiasmo generado por llegar a la verdad de las cosas, descubrir lo que realmente está pasando. El conocimiento de la verdad puede conducir a todo tipo de acciones y estas acciones pueden conducir a más verdades.

Este encuentro se celebró ... en un esfuerzo por educar a los jóvenes cuadros revolucionarios en los fundamentos de las relaciones de clase y la conciencia de clase para que pudieran, como ellos mismos dijeron, llegar a la raíz de la calamidad ... La reunión duró tres días y se discutieron tres grandes temas: 1) ¿Quién depende de quién vivir? 2) ¿Por qué los pobres son pobres y los ricos son ricos? 3) ¿Debe pagarse alquiler a los terratenientes? ... Cuando la reunión concluyó al tercer día, las tres preguntas principales se habían resuelto en la mayoría de las mentes. 1) Los terratenientes dependían del trabajo de los campesinos para su vida. 2) Los ricos eran ricos porque "pelaban y pelaban" a los pobres. 3) El alquiler no debe ser pagado a los terratenientes. William Hinton, FANSHEN, 1966

Pero ningún cambio particular en el comportamiento personal de una mujer, ni tampoco ninguna acción o estrategia particulares están presupuestos. Por la misma lógica de la idea ninguna acción puede ser requerida antes de tiempo en la concientización, a menos que un grupo esté usando la concientización específicamente como una tormenta de ideas para una acción. La idea es estudiar la situación para determinar qué tipos de acciones, individuales o políticas, son necesarias. Esto prácticamente 
también es cierto. Si las mujeres temen tener que tomar acción sobre aquello de lo que están hablando, especialmente acción solas, como individuos, no van a hablar de nada de lo que no estén listas para llevarlo a la acción inmediatamente, o no serían honestas. Hay que llevar a cabo acciones, pero a menudo hay que planificarlas, y a veces retrasarlas. De hecho, parte del porqué la concientización es el enfoque radical, es que las mujeres no vienen para tomar /acción inmediata. No podemos limitar nuestro pensamiento o nuestra acción sólo a lo que podemos hacer inmediatamente. La acción puede ser llevada a cabo, pero a menudo, debe ser planificada - y demorada. Al comienzo, nuestra idea era que el trabajo tanto a través de los grupos de concientización (C-R) como de las acciones que realizáramos, despertaría cada vez a más mujeres a la comprensión de cuáles eran sus problemas y esto las llevaría a la acción,

\section{Más citas}

Hemos preguntado a menudo, ¿Cuál es el uso de las convenciones? ¿Por qué hablar? ¿Por qué no trabajar? ¡Como si el pensamiento no hubiera precedido al acto! Aquellos que actúan sin pensar previamente, no son buenos para mucho. El pensamiento es primero adquirido, luego se expresa, y eso conduce a la acción; y la acción sustentada nunca debe ser revertida: es duradera y rentable y produce el efecto deseado. Sé que hay muchos que se aprovechan de este movimiento, $y$ dicen: "No están haciendo nada; sólo hablan" ¡Sí, haciendo nada! Sólo hemos arado la tierra y sembrado las semillas; están pagando los beneficios, y sin embargo nos dicen que no hemos hecho nada! Ernestine Rose, 1860, Historia del sufragio de las mujeres.

Kramer Nkrumah dijo: "El pensamiento sin la acción es vacío y la acción sin pensamientos es ciega." Él afirma que las revoluciones están hechas por hombres que piensan como hombres de acción y actúan como hombres de pensamiento. Esas son las únicas personas que hacen la revolución.

Stokely Carmichael. Akwesasne Notes, 1974

tanto en forma individual como colectiva. $Y$ eso ciertamente ocurrió, en una escala sin precedentes. Por supuesto, con mayor unidad y organización más puede ser logrado y solucionado. Pero las personas deben aprender esto, y hay más y más para aprender acerca de qué métodos de organización y acción necesitamos. Hay también más aclaraciones para hacer acerca de la 
clarificación de metas y la definición de obstáculos, al establecer conexiones entre la opresión de las mujeres y otros sistemas de opresión y explotación.

Analizar nuestra experiencia en nuestras vidas personales y en el movimiento, leer acerca de la experiencia de la lucha de otras personas, y conectarlos a través de la concientización puede mantenernos en el camino, moviéndonos tan rápido como sea posible hacia la liberación de las mujeres.

LECTURAS SUGERIDAS (siguiendo la forma de presentación en el original) "Program for Feminist Consciousness-Raising" by Kathie Sarachild (Nov. 1968). Publicado en forma completa en Notes from the Second Year: Women's Liberation, Shulamith Firestone, editor, 1970, NY (agotado). También varias partes en Voices from Women's Liberation (Tanner), Radical Therapist (Agel), Sisterhood is Powerful (Morgan), Women's Fate: Raps from a Feminist Consciousness-Raising Group (Dreifus). Ver apéndice.

"The Personal is Political" de Carol Hanisch (Fed., 1969). En Firestone; Agel. Ver apéndice.

"Principles" by Redstockings (April, 1969). En Morgan (erróneamente atribuido a New York Radical Women). Ver apéndice.

"Resistances to Consciousness" de Irene Peslikis (junio, 1969). En Firestone; Tanner; Morgan.

"Redstockings Manifesto" (julio 7, 1969). En Masculine/Feminine (Rozak \& Rozak); The Other Half (Epstein y J. Goode), 1971; Firestone; Morgan; Tanner. Ver apéndice. 
"False Consciousness" por Jennifer Gardner (Oct., 1969). En Tooth and Nail, 1969, Berkeley Calif.; Firestone; Tanner.

"Defining Reality" por Lynn O'Connor, Tooth and Nail, ibid.

"Redstockings West Manifesto" (Marzo 20, 1970), Rozak \& Rozak.

\section{LECTURAS PREPARATORIAS}

"The Women's Rights Movement in the U.S.A." de Shulamith Firestone (Junio, 1968). En Notes from the First Year, 1968, N.Y.: Tanner.

"Women of the World Unite -- We Have Nothing to Lose But Our Men!" by Carol Hanisch y Elizabeth Sutherland Martinez (Junio, 1968). En Notes from the First Year.

"Toward a Female Liberation Movement" de Beverly Jones y Judith Brown (Junio, 1968). Publicado por Southern Student Organizing Committee; New England Free Press; Tanner.

Malcolm X Speaks, George Breitman, editor, 1965.

Fanshen de William Hinton, 1968. 
Gráfico comparativo entre el liberalismo de izquierda, la revolución y el

liberalismo de derecha

\begin{tabular}{|c|c|c|}
\hline $\begin{array}{l}\text { Error } \\
\text { Liberalismo de } \\
\text { izquierda }\end{array}$ & Revolución & $\begin{array}{c}\text { Error } \\
\text { Liberalismo de } \\
\text { Derecha }\end{array}$ \\
\hline Grupos de estudio & $\begin{array}{c}\text { Grupos de } \\
\text { concientización }\end{array}$ & Grupos de charla \\
\hline $\begin{array}{c}\text { No hay investigación de } \\
\text { las cosas; conclusiones } \\
\text { preordenadas }\end{array}$ & $\begin{array}{l}\text { Investigación y } \\
\text { descubrimiento }\end{array}$ & $\begin{array}{c}\text { No hay investigación de } \\
\text { las cosas; conclusiones } \\
\text { preordenadas }\end{array}$ \\
\hline $\begin{array}{c}\text { Escolasticismo } \\
\text { (veneración por los } \\
\text { libros) }\end{array}$ & Ciencia (teoría) & Psicología \\
\hline $\begin{array}{c}\text { Generalizaciones } \\
\text { divorciadas de la } \\
\text { experiencia personal; } \\
\text { abstracciones }\end{array}$ & $\begin{array}{c}\text { Generalizaciones a } \\
\text { partir de la experiencia } \\
\text { personal e histórica }\end{array}$ & $\begin{array}{c}\text { Sólo la experiencia } \\
\text { personal, sin } \\
\text { generalizaciones; todo } \\
\text { concreto }\end{array}$ \\
\hline $\begin{array}{l}\text { Lo personal no es } \\
\text { político }\end{array}$ & Lo personal es politico & Lo politico es personal \\
\hline Dogmatismo & Radicalismo & Empirismo \\
\hline
\end{tabular}

